GOES, R.H.T.B. et al. Composição bromatológica e degradabilidade ruminal de resíduos da pré-limpeza de soja utilizados na alimentação de ovinos. PUBVET, Londrina, V. 5, N. 30, Ed. 177, Art. 1196, 2011.

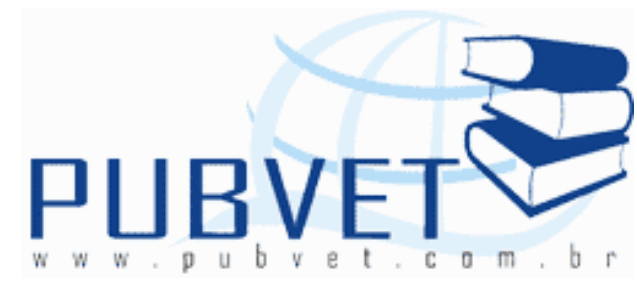

PUBVET, Publicações em Medicina Veterinária e Zootecnia.

\title{
Composição bromatológica e degradabilidade ruminal de resíduos da pré-limpeza de soja utilizados na alimentação de ovinos*
}

Rafael Henrique de Tonissi Buschinelli de Goes ${ }^{1}$; Rosiélen Augusto Patussi², Kennyson Alves de Souza ${ }^{3}$; Euclides Reuter de Oliveira'; Maria Gizelma de Menezes Gressler ${ }^{4}$; Hellen Leles Lima ${ }^{5}$; Kelly Cristina da Silva Brabes ${ }^{6}$; Andrea Maria de Araújo Gabriel ${ }^{1}$

${ }^{1}$ Docentes da FCA/UFGD, bolsista do CNPq

(rafaelgoes@ufgd.edu.br/rafaelgoes@cnpq.br);

${ }^{2}$ Aluna do programa de pós graduação PGZ/FCA/UFGD

(zoopatussi@hotmail.com);

${ }^{3}$ Aluno do curso de Zootecnia, FCA/UFGD, bolsista do CNPq

(kennysonalves@hotmail.com)

${ }^{4}$ Laboratório de Nutrição Animal, FCA/UFGD

5 Mestre em Zootecnia, FCA/UFGD, bolsista de extensão do CNPq (hellenmedvet@hotmail.com)

${ }^{6}$ Docente da FAEN/UFGD (kellybrabes@ufgd.edu.br)

*Trabalho de conclusão de curso do segundo autor. Trabalho financiado pelo CNPq. Fundect/MS e UFGD.

\section{Resumo}

Avaliou-se a degradabilidade ruminal pelo uso da técnica in situ, em ovinos, de resíduos da pré-limpeza da soja. Foram utilizados três ovinos da raça Santa 
GOES, R.H.T.B. et al. Composição bromatológica e degradabilidade ruminal de resíduos da pré-limpeza de soja utilizados na alimentação de ovinos. PUBVET, Londrina, V. 5, N. 30, Ed. 177, Art. 1196, 2011.

Inês com peso de $40 \mathrm{~kg}$, fistulados e providos de cânulas ruminais, mantidos em baias individuais. Os alimentos foram incubados em ordem decrescente de $72,48,24,18,12,3$ e 0 h. A fração solúvel da MS para ventilador foi de $13,82 \%$ e da PB 9,45\%, o que proporcionou baixa degradação ruminal para PB. O resíduo obtido na peneira comercial apresentou a maior quantidade de grãos e maior fração potencialmente degradável para PB e FDN $(85,42$ e $60,06 \%$ ), para a MS a degradabilidade foi de 42,19 com tempo de colonização de 7,76 $\mathrm{h}$. Os resíduos avaliados apresentaram baixa degradabilidade ruminal para MS, PB e FDN.

Palavras-chave: alimento alternativo, FDN, proteína bruta, tempo de colonização.

\section{Chemical composition and in situ ruminal degradability of residue from soybean dryer precleaning}

\section{Abstract}

We evaluated the degradability by the in situ technique in sheeps residues of pre-cleaning soybeans. Three Santa Ines sheep's weighing $40 \mathrm{~kg}$ fistulated and fitted with rumen cannulas were kept in individual stalls, were used. Foods were incubated in descending order of $72,48,24,18,12,3$ and $0 \mathrm{~h}$. The soluble fraction of DM for "ventilator" was $13.82 \%$ and $9.45 \% \mathrm{CP}$, which provides lower ruminal degradation of CP. The residue obtained on commercial sieve with presents the highest grains and higher potentially degradable fraction of CP and NDF (85.42 and 60.06\%), the DM degradability was 42.19 with colonization time of $7.76 \mathrm{~h}$. All the residues evaluated presented low degradability for DM, CP and NDF.

Keywords: alternative feed, colonization time, crude protein, NDF

\section{INTRODUÇÃO}

O aumento dos preços dos alimentos energéticos e protéicos para a alimentação animal elevou o custo de produção e reduziu a margem de lucro 
GOES, R.H.T.B. et al. Composição bromatológica e degradabilidade ruminal de resíduos da pré-limpeza de soja utilizados na alimentação de ovinos. PUBVET, Londrina, V. 5, N. 30, Ed. 177, Art. 1196, 2011.

para os produtores. Com isso, subprodutos das agroindústrias têm recebido atenção especial, uma vez que apresentam baixo custo de aquisição. A indústria de processamento de alimentos produz grandes quantidades de resíduos desperdiçados, mas possuem valores nutritivos potenciais e podem ser utilizados na alimentação animal (Goes et al., 2008).

Os resíduos na produção agrícola e na agroindústria necessitam de estudos para serem mais bem aproveitados na alimentação dos animais domésticos. Esta justificativa se fundamenta na necessidade de se fornecerem alimentos alternativos e viáveis economicamente, aos animais, sem concorrer diretamente com alimentação humana. Vários subprodutos originados de processamentos nas indústrias têm potencial de uso, principalmente para os animais ruminantes, e na maioria dos casos com redução nos custos de produção.

Com o aumento da demanda de carne ovina, tornou-se necessário a intensificação da produção para o abate de animais precoces; por se tratar de uma categoria que tem uma exigência nutricional muito elevada, devido à alta deposição de músculos e crescimento ósseo, a utilização de dietas com elevados níveis de concentrados são cada vez mais comuns. A alimentação, no caso de ovinos confinados é responsável por cerca de $70 \%$ dos custos de produção, obrigando os produtores a procurarem medidas que diminuam os custos de alimentação, com o uso de alimentos alternativos, como resíduos agroindústriais.

Quando se trata de criação em sistema extensivo (a pasto), a produção, muitas vezes é afetada pela inconstância da disponibilidade de pastagens no decorrer do ano, tanto quantitativa quanto qualitativamente. Uma vez que o principal objetivo da produção a pasto é o custo reduzido, têm-se mais uma vez, a importância do uso de fontes alternativas resultando em concentrados de baixo custo que proporcionem taxas compatíveis de desempenho animal com boa lucratividade (Lopes, et al., 2007).

O resíduo da pré-limpeza de soja é encontrado em grande quantidade no pátio das indústrias de beneficiamento e dos secadores das fazendas, 
GOES, R.H.T.B. et al. Composição bromatológica e degradabilidade ruminal de resíduos da pré-limpeza de soja utilizados na alimentação de ovinos. PUBVET, Londrina, V. 5, N. 30, Ed. 177, Art. 1196, 2011.

acarretando sérios transtornos caso não seja removido para locais mais afastados antes que o processo de fermentação se inicie. Pelo fato de ser um material com considerável valor nutritivo - teor de proteína superior a 34\% esse resíduo vem se destacando como fonte alternativa na alimentação de ruminantes, substituindo os alimentos concentrados tradicionais como o milho e o farelo de soja (Oliveira, et al., 2006).

O desempenho animal depende em grande parte do balanceamento correto da dieta. Dessa forma, torna-se indispensável o perfeito conhecimento do valor nutritivo dos alimentos que compõem a mesma. No entanto, informações técnico-científicas sobre o valor nutritivo desses subprodutos são escassas.

Dentre os métodos de avaliação de alimentos para ruminantes, a técnica in situ tem se destacado, por ser precisa e apresentar menor custo que as técnicas in vivo (Nocek, 1988). No Brasil, são realizados estudos com essa técnica para avaliar forragens, resíduos agrícolas e produtos industriais, na alimentação de bovinos (Goes et al., 2004).

Levando em conta essas informações, e buscando novas alternativas para a alimentação de ovinos, com o presente trabalho objetivou-se a determinação dos padrões da cinética de degradação ruminal e composição bromatológica de resíduos da pré-limpeza de soja.

\section{MATERIAL E MÉTODOS}

O experimento foi conduzido nas dependências do Laboratório de Nutrição Animal da Faculdade de Ciências Agrárias da Universidade Federal da Grande Dourados.

Os resíduos avaliados foram obtidos na Fazenda Maggioni I, localizada em Ponta Porã, Mato Grosso do Sul, e previamente submetido à análise física com auxílio de lupa, para identificação e quantificação dos componentes do resíduo. 
GOES, R.H.T.B. et al. Composição bromatológica e degradabilidade ruminal de resíduos da pré-limpeza de soja utilizados na alimentação de ovinos. PUBVET, Londrina, V. 5, N. 30, Ed. 177, Art. 1196, 2011.

Os resíduos avaliados foram classificados de acordo com as etapas do processo de pré-limpeza da soja para a comercialização e identificados como Moega, Ventilador e Peneira comercial.

Para a determinação da degradabilidade in situ foram utilizados três ovinos da raça Santa Inês, com $40 \mathrm{~kg}$ de peso vivo, castrados, fistulados e providos de cânula ruminal, mantidos em baias individuais, recebendo ração concentrada e capim picado (Brachiaria brizantha cV Marandu), como volumoso, na proporção de 40:60.

Os alimentos foram moídos em peneira de crivo de $1 \mathrm{~mm}$ para a determinação dos teores de matéria seca (MS), proteína bruta (PB), fibra em detergente neutro (FDN) e Ácido (FDA), lignina (LIG), segundo metodologias descritas por Silva e Queiroz (2002).

Para a determinação da degradabilidade in situ os alimentos foram moídos em moinhos de facas, em peneira de $5 \mathrm{~mm}$, e posteriormente secos a $65^{\circ} \mathrm{C}$, por 24 horas, retirados, e pesados. Após pesagem os alimentos foram colocados em sacos de náilon, de $5 \times 10 \mathrm{~cm}$ de área livre, com $50 \mu$ de porosidade, na quantidade $2,0 \mathrm{~g}$, respeitando a relação de $20 \mathrm{mg} / \mathrm{cm}^{2}$. Os saquinhos foram fechados e secos a $65^{\circ} \mathrm{C}$ por 24 h., pesados, e colocados em sacolas de filó, medindo, $15 \times 30 \mathrm{~cm}$, com um pequeno peso de chumbo de $100 \mathrm{~g}$. A sacola foi amarrada a uma linha de náilon de aproximadamente $0,5 \mathrm{~m}$ de comprimento livre. Todas as amostras foram preparadas segundo as recomendações propostas por Nocek (1988).

As sacolas foram introduzidas diretamente no rúmen, em ordem decrescente de $72,48,24,18,12,3$ e 0 h., em triplicatas por animal/tempo de incubação, conforme NRC (2001). No tempo de 0 h., os saquinhos foram pré-incubados num recipiente com água.

Os dados sobre desaparecimento da matéria seca e proteína bruta foram calculados baseando-se na diferença entre o peso incubado e os resíduos após a incubação. Para a estimativa dos parâmetros cinéticos da MS, PB e FDN foi utilizado o modelo assintótico de primeira ordem proposto por Orskov \& McDonald, (1979): DP $=a+b\left(1-e^{-c t}\right)$; onde DP é a degradabilidade 
GOES, R.H.T.B. et al. Composição bromatológica e degradabilidade ruminal de resíduos da pré-limpeza de soja utilizados na alimentação de ovinos. PUBVET, Londrina, V. 5, N. 30, Ed. 177, Art. 1196, 2011.

ruminal potencial dos alimentos; "a" é a fração solúvel; "b", a fração potencialmente degradável da fração insolúvel que seria degradada a uma taxa "c"; "c", que seria a taxa de degradação da fração "b"; e "t" o tempo de incubação em horas. A fração considerada indegradável foi calculada da seguinte forma: $\mathrm{I}=(100-(a+b))$.

Para se estimar a degradabilidade efetiva $(D E)$, foi utilizado o modelo matemático: $\mathrm{DE}=\mathrm{a}+[(\mathrm{b} * \mathrm{c}) /(\mathrm{c}+\mathrm{K})]$; em que $\mathrm{K}$ é a taxa de passagem de sólidos pelo rúmen, definida aqui como sendo de 2,5 e 8,0\%/h., que pode ser atribuído ao nível de consumo alimentar baixo, médio e alto. Após os dados serem ajustados ao modelo e utilizando-se o valor desaparecimento obtido no tempo zero ( $\left.a^{\prime}\right)$, foi estimado o tempo de colonização (TC) para a MS, PB e FDN segundo adequação proposta por Patiño et al., (2001): TC $=\left[-\ln \left(a^{\prime}-a-\right.\right.$ b)/c], onde os parâmetros a, b, e c foram estimados pelo algorítimo de Gaus Newton.

As curvas de degradação da MS, PB e FDN dos alimentos avaliados, para cada animal utilizado, foram submetidas ao ajuste pelos respectivos modelos utilizando-se o procedimento "Regressão Não Linear" do Software SAEG 9.1, o que permitiu a obtenção dos parâmetros analisados.

\section{RESULTADOS E DISCUSSÃO}

Os resíduos apresentaram elevado teor de PB e FDN (Tabela 1). O resíduo resultante do Ventilador apresentou os maiores valores para FDN e FDA, 45,67 e 40,54\%, respectivamente. Os resíduos obtidos na Moega e na Peneira Comercial apresentaram FDN de 41,13 e 38,51\%; respectivamente. $\mathrm{O}$ valor médio para a PB (38,39\%) foi superior ao encontrado por Oliveira et al. (2006), de 33,50\%. O teor de extrato etéreo foi maior para o resíduo classificado como peneira comercial, principalmente pela maior presença de grãos de soja inteiros e quebrados. 
GOES, R.H.T.B. et al. Composição bromatológica e degradabilidade ruminal de resíduos da pré-limpeza de soja utilizados na alimentação de ovinos. PUBVET, Londrina, V. 5, N. 30, Ed. 177, Art. 1196, 2011.

Tabela 1: Composição bromatológica dos resíduos da pré-limpeza da soja, em percentagem de MS

\begin{tabular}{lcccccc}
\hline Resíduos & $\%$ MS & \%PB & \%FDN & \%FDA & \%LIG & $\%$ EE \\
\hline Moega & 92,38 & 39,82 & 41,13 & 32,00 & 17,97 & 10,24 \\
Ventilador & 92,48 & 34,26 & 45,67 & 40,54 & 15,63 & 16,79 \\
Peneira comercial & 92,86 & 41,11 & 38,51 & 35,43 & 2,169 & 20,50 \\
\hline * MS = matéria seca, PB = proteína bruta, FDN = fibra em detergente neutro, \\
FDA = fibra em detergente ácido, LIG= lignina; EE=extrato etéreo.
\end{tabular}

Côrtes e Côrtes, (1993) classificam os resíduos da pré-limpeza de soja em resíduos fibrosos grossos e finos, com a seguinte composição: a) resíduo grosso: $18,3 \%$ de proteína bruta (PB); 38,6\% de fibra bruta (FB); 46,4\% de fibra em detergente ácido (FDA); 58,8\% de fibra em detergente neutro (FDN) e $11 \%$ de lignina: b) resíduos finos: $17,4 \%$ de $\mathrm{PB} ; 32,3 \%$ de $\mathrm{FB} ; 45,5 \%$ de FDA; $56,8 \%$ de FDN e $14,0 \%$ de lignina. Os teores de lignina encontrados neste trabalho foram superiores ao encontrado por estes autores, possivelmente em função da composição física apresentada pelos resíduos.

A composição química pode sofrer interferência da composição física, uma vez que para cada etapa de limpeza há diferença na quantidade de fragmentos de insetos, casca de soja, grãos inteiros, grãos quebrados, grãos não desenvolvidos, sementes diversas, fragmentos de vagem e caule e terra (Tabela 2).

Observa-se que somente o resíduo designado de peneira comercial apresenta grãos de soja inteiros (Tabela 2), mostrando-se com maior potencial de uso na alimentação animal. Bergamashine et al., (1999) observaram 42,2\% de grãos de soja presente no resíduo, valor este inferior ao encontrado neste trabalho se somarmos a proporção de grãos inteiros e quebrados $(78,68 \%)$. 
GOES, R.H.T.B. et al. Composição bromatológica e degradabilidade ruminal de resíduos da pré-limpeza de soja utilizados na alimentação de ovinos. PUBVET, Londrina, V. 5, N. 30, Ed. 177, Art. 1196, 2011.

Tabela 2: Análise física do resíduo de soja e composição em \%.

\begin{tabular}{lccc}
\hline Componentes & Moega & Ventilador & Peneira \\
\hline Fragmentos de insetos & 0,54 & 1,28 & 0,56 \\
Casca de soja & 0,93 & 8,27 & 6,72 \\
Grãos inteiros & - & - & 34,11 \\
Grãos quebrados & - & - & 44,57 \\
Grãos não desenvolvidos & 82,87 & 17,70 & - \\
Sementes diversas & 9,03 & 4,75 & 2,47 \\
Fragmentos de vagem e caule da soja & 2,12 & 67,97 & 11,54 \\
Terra & 4,47 & - & - \\
\hline
\end{tabular}

Quanto a fração solúvel (a), verificou-se baixo valor para os nutrientes analisados (Tabelas 3 e 4 ). Os maiores valores foram apresentados pelo resíduo denominado peneira comercial, sendo este superior ao resíduo da moega e do ventilador em 60,12 e 101,12\%, respectivamente. Associado a maior fração solúvel a maior taxa de degradação da peneira comercial acarretou maiores valores de degradabilidade efetiva. A fração solúvel obtida pela peneira comercial foi semelhante ao obtido por Bergamaschine et al. (1999) para MS $(23,15 \%)$ e inferiores para a PB $(27,76 \%)$, isto pode estar associado a composição bromatológica dos alimentos avaliados (Tabela 1).

A degradabilidade ruminal efetiva da peneira comercial para matéria seca foi de $42,19 \%$ que esta diretamente relacionada com o tempo de colonização de 7,76 h que foi o menor entre os alimentos avaliados (Tabela 6). A degradabilidade potencial para a MS e PB foi maior para peneira comercial, decorrente da maior fração solúvel e taxa de degradação da fração "b" (Figura 1 e 2). Podendo ser explicada devido à baixa quantidade de vagem (fibra) encontrada nessa etapa da pré-limpeza. A baixa degradabilidade apresentada por todos os nutrientes pode ser decorrente dos altos teores de fibra apresentados pelos resíduos (Tabela 1 ). 
GOES, R.H.T.B. et al. Composição bromatológica e degradabilidade ruminal de resíduos da pré-limpeza de soja utilizados na alimentação de ovinos. PUBVET, Londrina, V. 5, N. 30, Ed. 177, Art. 1196, 2011.

Tabela 3. Parâmetros cinéticos da degradação in situ, para a matéria seca dos alimentos avaliados.

\begin{tabular}{lcccc|cccc}
\hline Alimentos & \multicolumn{4}{c|}{ Parâmetros } & \multicolumn{4}{c}{ DE (\%/h) } \\
\hline \multirow{3}{*}{ Moega } & $\mathrm{a}(\%)$ & $\mathrm{b}(\%)$ & $\mathrm{c}(\% / \mathrm{h})$ & $\mathrm{I}(\%)$ & 2 & 5 & 8 & $\mathrm{r}^{2}$ \\
\cline { 2 - 8 } Ventilador & 17,43 & 55,47 & 0,018 & 27,10 & 43,55 & 31,99 & 27,53 & 0,92 \\
Peneira comercial & 13,82 & 61,78 & 0,019 & 24,40 & 43,67 & 30,64 & 25,53 & 0,95 \\
\hline
\end{tabular}

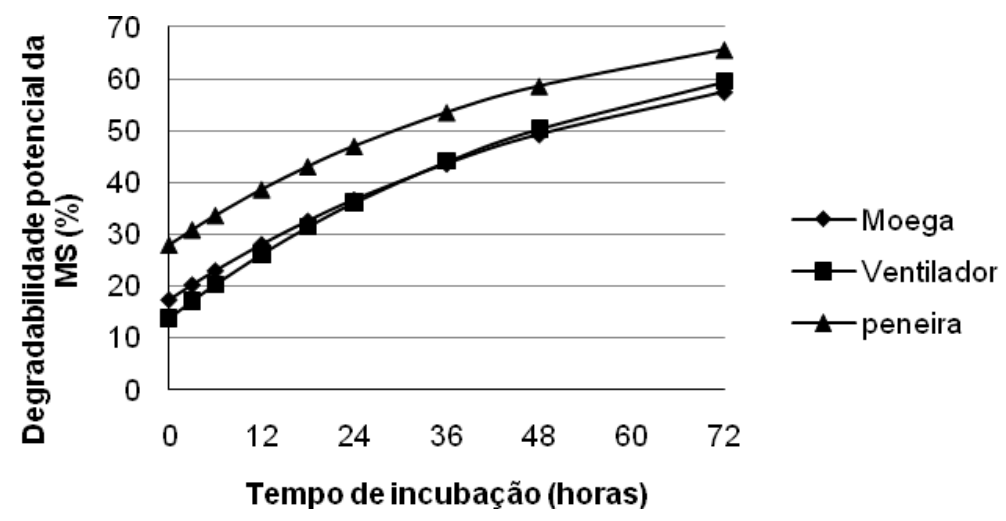

Figura 1. Degradabilidade Potencial da Matéria Seca (\%)

TABELA 4. Parâmetros cinéticos da degradação in situ para a proteína bruta dos alimentos avaliados.

\begin{tabular}{lcccc|cccc}
\hline Alimentos & \multicolumn{4}{c|}{ Parâmetros } & \multicolumn{4}{c}{$\mathrm{DE}(\% / \mathrm{h})$} \\
\hline \multirow{3}{*}{ Moega } & $\mathrm{a}(\%)$ & $\mathrm{b}(\%)$ & $\mathrm{c}(\% / \mathrm{h})$ & $\mathrm{I}(\%)$ & 2 & 5 & 8 & $\mathrm{r}^{2}$ \\
\cline { 2 - 8 } Ventilador & 12,69 & 49,43 & 0,006 & 37,88 & 24,10 & 17,99 & 16,14 & 0,60 \\
Peneira comercial & 9,45 & 65,27 & 0,018 & 25,28 & 39,91 & 26,37 & 21,17 & 0,93 \\
& 13,42 & 85,42 & 0,015 & 1,16 & 50,03 & 33,13 & 26,91 & 0,91 \\
\hline
\end{tabular}


GOES, R.H.T.B. et al. Composição bromatológica e degradabilidade ruminal de resíduos da pré-limpeza de soja utilizados na alimentação de ovinos. PUBVET, Londrina, V. 5, N. 30, Ed. 177, Art. 1196, 2011.

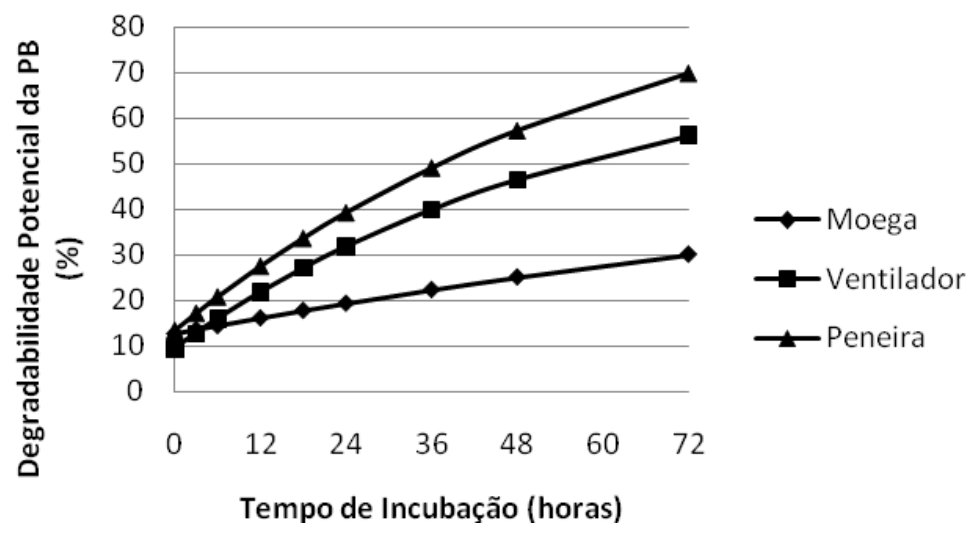

Figura 2. Degradabilidade Ruminal Potencial na Proteína Bruta (\%)

A FDN apresentou baixos valores de degradabilidade ruminal decorrente da baixa fração solúvel e baixa taxa de degradação apresentada para todos os alimentos (Tabela 5 e Figura 3). O comportamento da digestibilidade da fibra em detergente neutro pode ser reflexo dos teores de extrato etéreo; que pode ter efeito depressor sobre a degradabilidade da fibra.

Tabela 5. Parâmetros cinéticos da degradação in situ para a FDN dos alimentos avaliados.

\begin{tabular}{lcccc|cccc}
\hline Alimentos & \multicolumn{4}{c|}{ Parâmetros } & \multicolumn{4}{c}{$\mathrm{DE}(\% / \mathrm{h})$} \\
\cline { 2 - 8 } & $\mathrm{a}(\%)$ & $\mathrm{b}(\%)$ & $\mathrm{c}(\% / \mathrm{h})$ & $\mathrm{I}(\%)$ & 2 & 5 & 8 & $\mathrm{r}^{2}$ \\
\hline Moega & 8,24 & 34,14 & 0,004 & 57,62 & 13,69 & 10,65 & 9,79 & 0,92 \\
Ventilador & 5,43 & 58,22 & 0,016 & 36,35 & 31,12 & 19,41 & 15,03 & 0,94 \\
Peneira comercial & 13,93 & 60,06 & 0,013 & 26,01 & 37,81 & 26,47 & 22,44 & 0,95 \\
\hline
\end{tabular}


GOES, R.H.T.B. et al. Composição bromatológica e degradabilidade ruminal de resíduos da pré-limpeza de soja utilizados na alimentação de ovinos. PUBVET, Londrina, V. 5, N. 30, Ed. 177, Art. 1196, 2011.

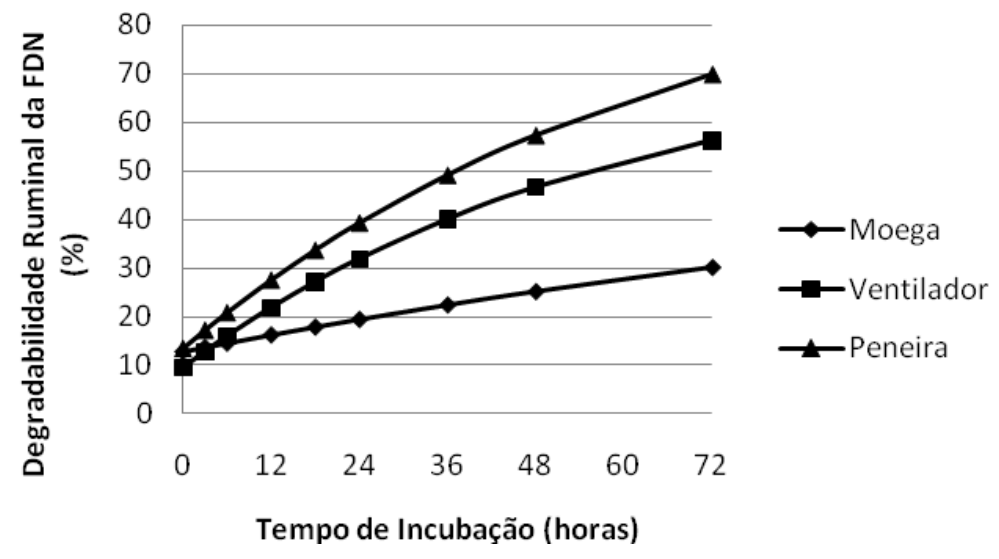

Figura 3. Degradabilidade Potencial da Fibra em Detergente Neutro (\%)

Para a matéria seca a peneira comercial apresentou o menor tempo de colonização, seguida pela moega (Tabela 6); o que pode contribuir para maior degradação da matéria seca para este alimento. O tempo máximo de colonização apresentado corresponde à moega para FDN, o que pode ter influenciado na baixa degradação ruminal deste alimento.

Tabela 6: Tempo de colonização (h) para matéria seca (MS), proteína bruta (PB) e fibra em detergente neutro (FDN) dos alimentos avaliados

\begin{tabular}{lrrr}
\hline & \multicolumn{3}{c}{ Tempo de colonização TC $(\mathrm{h})$} \\
\cline { 2 - 4 } Alimentos & MS & PB & FDN \\
\hline Moega & 8,04 & 9,02 & 9,10 \\
Ventilador & 8,10 & 8,22 & 8,11 \\
Peneira Comercial & 7,76 & 8,65 & 8,42 \\
\hline
\end{tabular}

Horários de incubação menores em relação ao tempo de colonização fazem com que a curva de degradação aumente a sua curvatura aumentando a assíntota com conseqüente diminuição na taxa de degradação (Dhanoa, 1988), 
GOES, R.H.T.B. et al. Composição bromatológica e degradabilidade ruminal de resíduos da pré-limpeza de soja utilizados na alimentação de ovinos. PUBVET, Londrina, V. 5, N. 30, Ed. 177, Art. 1196, 2011.

o que pode explicar os valores de degradação dos alimentos avaliados (Tabelas $3,4$ e 5$)$.

\section{CONCLUSÕES}

Os resíduos da pré- limpeza dos grãos de soja apresentaram baixa degradabilidade ruminal para matéria seca (MS), proteína bruta (PB) e fibra em detergente neutro (FDN). O resíduo da Peneira Comercial apresentou a melhor composição bromatológica quando comparado aos outros resíduos, em função da composição física do mesmo.

Os resíduos da pré-limpeza da soja podem constituir uma alternativa para a alimentação ovina, devendo ser realizada mais estudos.

\section{AGRADECIMENTOS}

Ao CNPq, FUNDECT/MS e UFGD, pelas bolsas concedidas; à Milena Soto Maggioni Rosa pela doação dos alimentos avaliados neste trabalho, à André Azambuja pela doação dos animais utilizados neste trabalho e ao Prof. Fernando Arevalo Garcia, pela realização da cirurgia para implantação das cânulas ruminais.

\section{REFERÊNCIAS BIBLIOGRÁFICAS}

BERGAMASHINE, A.F.; VALÉRIO FILHO, W. V., DUARTE, E. F. Degradabilidade "in situ" e digestibilidade "in vivo" do resíduo do pré-processamento da soja (Glycine max (L.) merrill). Ciência e Agrotecnologia, v. 23, n.3, p. 724-732, 1999.

CORTES, N.A.; CORTES, J.A.A. Conservação e utilização de reíduos úmidos da pré limpeza de soja, na alimentação de bovinos. EMPAER, MT., 1993. 21p. (Boletim de pesquisa, 03).

DHANOA, M.S. On the analysis of draconbag data for low degradability feed. Grass and Forage Science, v.43, p.441-444. 1988.

GOES, R.H.T.B; TRAMONTINI. R.C.M.; ALMEIDA. G.D.; CARDIM, S.T.; RIBEIRO, J.; OLIVEIRA. L.A.; MOROTTI. F.; BRABES. K.C.S.; OLIVEIRA. E.R. Degradabilidade ruminal da matéria seca e proteína bruta de diferentes subprodutos agroindustriais utilizados na alimentação de bovinos. Revista Brasileira de Saúde e Produção Animal. An., v.9, n.3, p. 715-725, 2008. 
GOES, R.H.T.B.; MANCIO, A.B.; VALADARES FILHO, S.C.; LANA, R.P. Degradação ruminal da matéria seca e proteína bruta, de alimentos concentrados utilizados como suplementos para novilhos. Ciência e Agrotecnologia, v.28, n.1, p.167-173, 2004.

LOPES, L.S.; RESENDE, C.A.P.; CHALFUN, L.T.F.; MATA JÚNIOR, J.I.; CHALFUN, L.H.L.; BABILÔNIA, J.L. Desempenho de bovinos confinados alimentados com resíduo amonizado da Pré-limpeza de soja associado à cana-de-açúcar. IN: Anais Zootec, Londrina, ABZ. CDROOM. 2007.

NATIONAL RESEARCH COUNCIL -NRC. Nutrient requirements of dairy cattle. 7ed. Washington: National Academy Press, 2001. 381p.

NOCEK, J.E. In situ and others methods to estimate ruminal protein and energy digestibility. Journal Dairy Science, v.71, p. 2051-2069, 1988.

OLIVEIRA, E.R.; BABILÔNIA, J.L.; PAIVA, P.C.A.; MORON, I.; FERREIRA, I.C. Cinética da degradabildiade ruminal in situ do resíduo amonizado da pré-limpeza dos secadores de soja. Veterinária em Foco, v.3, n.2. p.194-189, 2006.

ORSKOV, E.R.; MCDONALD, I. The estimation of protein degradability in the rumen from incubation measurements weighted according to rate of passage. Journal Agriculture Science, v.92, n.1. p. 499-508, 1979

PATINÕ, H.O.; LANGWINSKI, D.; SILVEIRA, A.L.F.; SILVA, N.L.Q. Avaliação de métodos de ajuste da curva de degradação ruminal da FDN em forragens. IN: Reunião Anual da Sociedade Brasileira de Zootecnia, 38, 2001, Piracicaba, 2001, p.970.

SILVA, D.J. \& QUEIROZ, A.C. Análise de alimentos: métodos químicos e biológicos. Viçosa, MG: Editora UFV, 2002. 235p. 